\title{
Performance Of Deterministic And Stochastic Trends Models In Forecasting The Behavior Of The Canadian Dollar And The Japanese Yen Against The US Dollar
}

Arav Ouandlous, (Email: ouandlou@savstate.edu), Savannah State University

\begin{abstract}
The literature on modeling and forecasting exchange rate behavior shows that complex forecasting exchange rate models do not often outperform ARIMA models. We show that the same forecasting models applied to forecast the behavior of the Canadian dollar and the Japanese Yen against the US dollar produced varying forecast performance.
\end{abstract}

\section{INTRODUCTION}

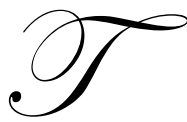

he literature on modeling and forecasting exchange rate behavior shows that complex and sophisticated forecasting exchange rate models such as vector autoregression (VAR) models do not have a significant predictive power over the simple and less costly autoregressive integrated moving average (ARIMA) models. In several instances, it was shown that the latter provided even better results than those of the former. Furthermore, we show in this paper that the same forecasting models such as the deterministic and stochastic trends models used here to forecast the behavior of the Canadian dollar and the Japanese Yen against the US dollar produced varying forecast performance.

Exchange rates have been shown to influence and to be influenced by macroeconomic variables such as output, inflation, interest rates, and particularly by imports and exports. We selected to forecast the Canadian Dollar and the Japanese Yen because Canada and Japan are among the top trading partners of the United States who have consistently shown, over this past decade, a trade surplus with the United States. To treat this topic, we organized our paper as follows. The first section deals with a brief review of the literature; the second with data and modeling; the third with forecast outcomes and their interpretation, and the fourth section with a brief conclusion.

\section{BRIEF REVIEW OF THE LITERATURE}

Exchange rates are shown to be one of the most challenging and difficult economic variables to accurately predict. They elude both academicians and practitioners alike. There is a plethora of forecasting models ranging from the simplest ones to the most complex and sophisticated ones with varying quality and predictive power. Some models do well and others do not.

This paradoxical situation has divided researchers into two major groups. The group which believes that the more disaggregated intraday data and the more complex and sophisticated the models are the better will be the performance of the forecasting models; and the second group which believes that the models do not do well because they do not include the "right" variables and therefore cannot predict accurately the behavior of exchange rates (Neely and Sarno, p.21, 2003) ${ }^{1}$ 
The Monetarists models such as the stickey-price overshooting exchange rate model (Dornbush, 1976) ${ }^{2}$ and the non sticky price models which used to be the dominant based forecasting exchange rate models in the 1970's and 1980's proved later to explain very little of the variation in exchange rates behavior; " ...the amount of exchange rate variation explained by monetary models is at most-small." ( Neely and Sarno.) ${ }^{3}$

The vector autoregressive models (VAR) were for a while the dominant forecasting models; however, they proved to be complex, costly, and with varying predictive performance. The models based on the random walk hypothesis became very popular and promising. Their forecasting performance has been also mixed. They produced poor forecasts in the short run and strong forecast in the long run. It is believed that the larger is the error estimation bias, the better is the predictability of random walk models (Ross, 2005), and the application of a non linear exponential smooth transition autoregressive model could improve not the short run but the long run predictability of real exchange rates behavior (Sin Chen etc, 2003) ${ }^{4}$ and (Richard and Lucio, 2003) ${ }^{5}$.

The assumption that real exchange rates changes follow a nonlinear process has led to a flurry of articles and to new statistical methods of modeling exchange rates. ARCH, GARCH, and ARIMA models are widely used to capture the volatility inherent in the exchange rate behavior. The results are also mixed.

New methods such as wavelets techniques (Wong, Wein, 2003) ${ }^{6}$ have yet to prove their forecasting reliability; and the Bayesian Vector Error Correction Models (Sin Chen and Mark Leung, 2003), which were shown to improve out-of-sample forecast, perform poorly on in-sample forecasts. The Artificial neural network models have yet to prove their effectiveness. By themselves these models produced less reliable forecasts; and the factors that should be included in these models have not received a wide acceptance by the academic community (Neely and Sarno, 2003) ${ }^{7}$ and (Huang and al. 2004) ${ }^{8}$.

Recently, however, the focus has turned to interval estimation and to a highly disaggregated time series data such as high frequency intraday, which is believed to improve the reliability and accuracy of the forecasting models. Anderson, Bollerslev, Diebold, and Labys $(2003)^{9}$ are among the leaders in this field. They believe that the theory of continuous-time arbitrage free-price processes and the theory of quadratic variation to modeling the behavior of exchange will lead to a significant improvement in the reliability of the models' forecasts.

This brief review of the literature reveals that forecasting exchange rates is still a mixture of art and science. There is no model that fits all. Finding the best model remains the most challenging task of the model builder. In the next section we present our models and data with points and interval estimation forecasts.

\section{MODELS AND DESCRIPTION OF THE DATA}

We follow closely Diebold's methodology in the application of deterministic and stochastic trends models in forecasting the behavior of the Canadian Dollar and the Japanese Yen against the US Dollar (Diebold, 2003, 2004) ${ }^{10}$. Because of the limited space we omitted the theoretical description of these models and refer the reader to the vast literature existing on the subject. Since exchange rates are known for their volatility, the stochastic trends models are believed to describe well their behavior. We remind the reader that for the covariance to be stationary in an ARMA (p, q) process all the roots must be located outside the unit circle and the first difference assures the covariance stationarity and invertibility (Diebold, 2004) ${ }^{11}$.

The data we use in this paper are monthly data from 1971:1 to 2004:11 for the Canadian Dollar and the Japanese Yen against the US Dollar Exchange Rate. Let's apply our models to forecast the behavior of thee two exchange rates. 


\section{Deterministic Model And Data Description}

Graphical Presentation Of The Canadian Dollar Exchange Rates Data

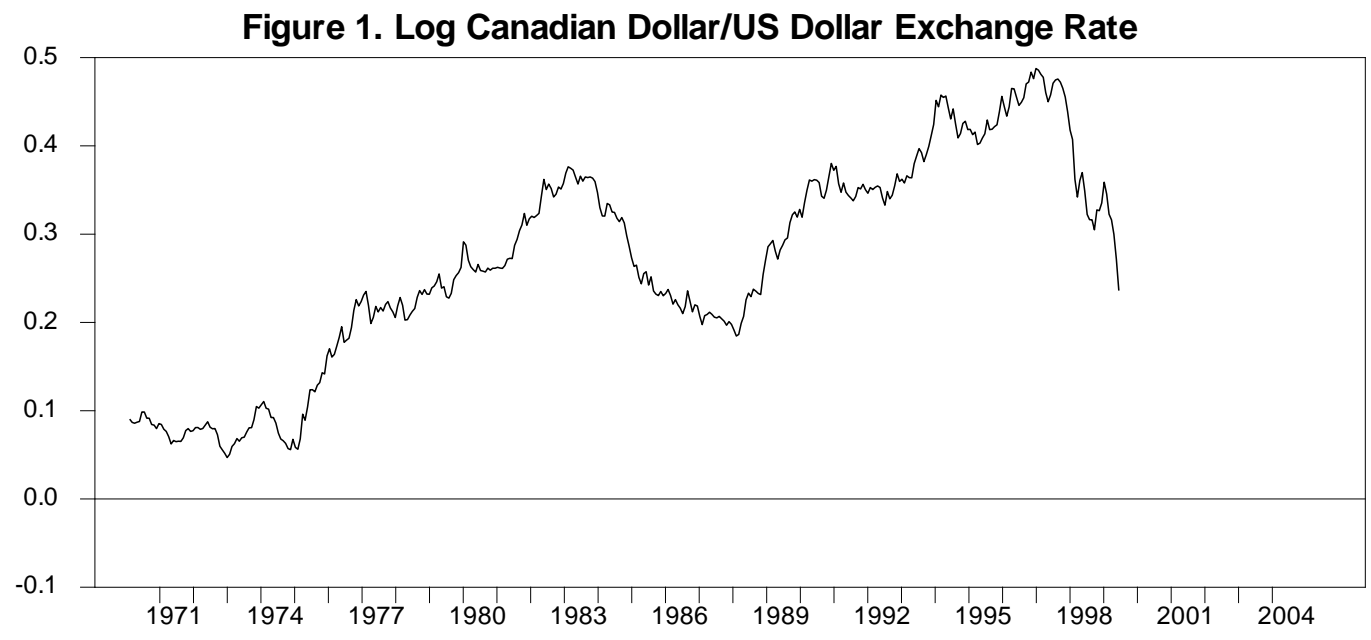

Graphical Presentation Of The Japanese Yen Exchange Rates Data

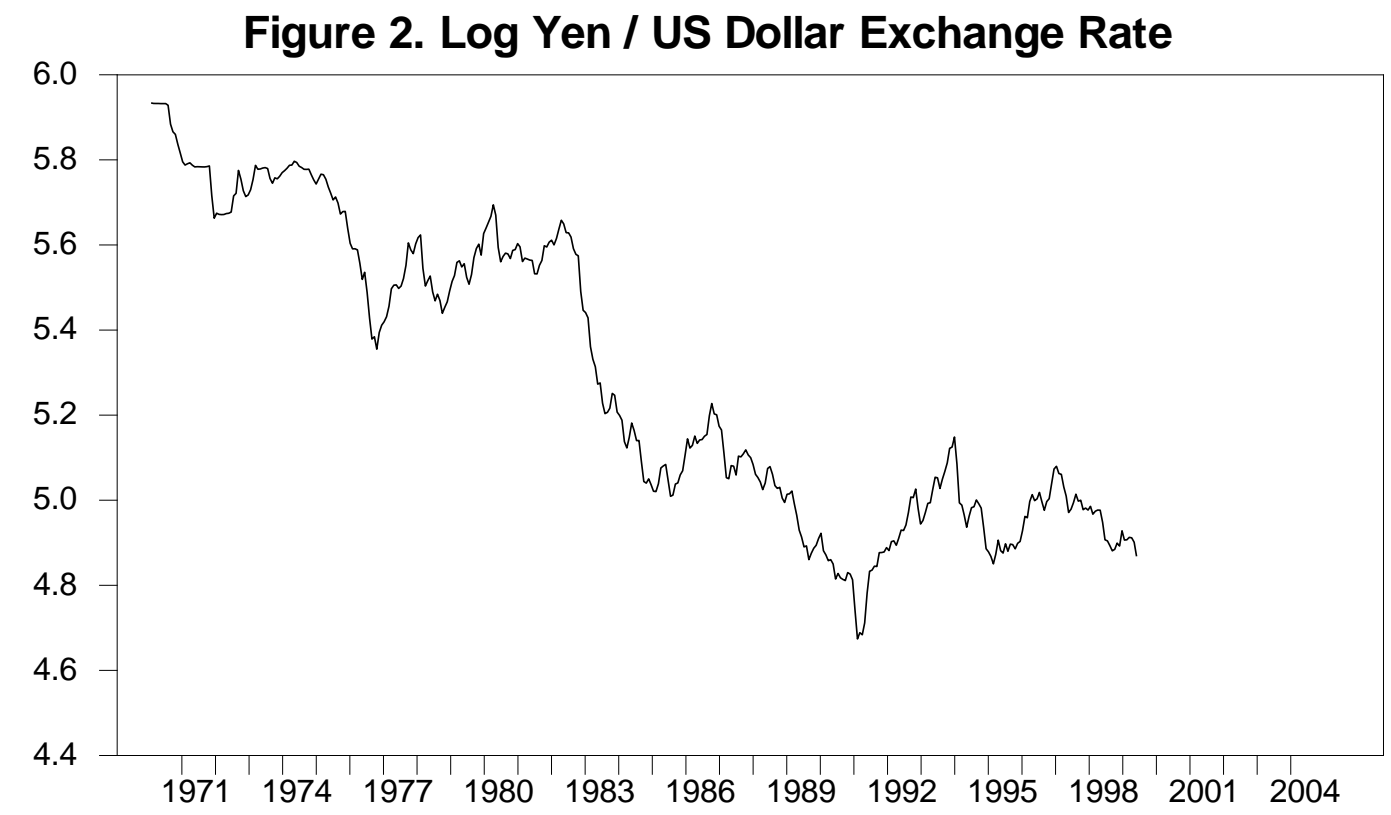

Both of theses graphs show that the series are highly persistent which may indicate the presence of unit root. Because of this persistence, we will investigate the changes in their differences. 
Sample And Partial Autocorrealtion Coefficient Of The Logarithm Of The Canadian Dollar

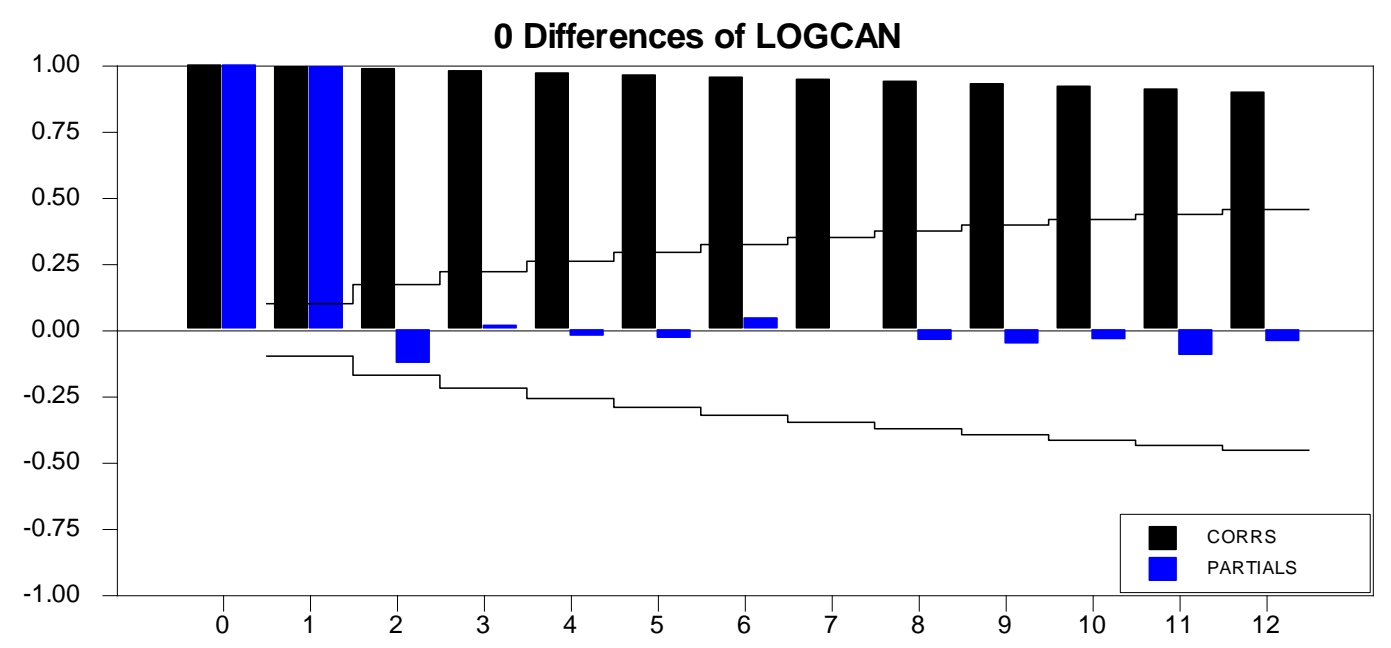

Sample And Partial Autocorrealtion: The Logarithm Of The Japanese Yen

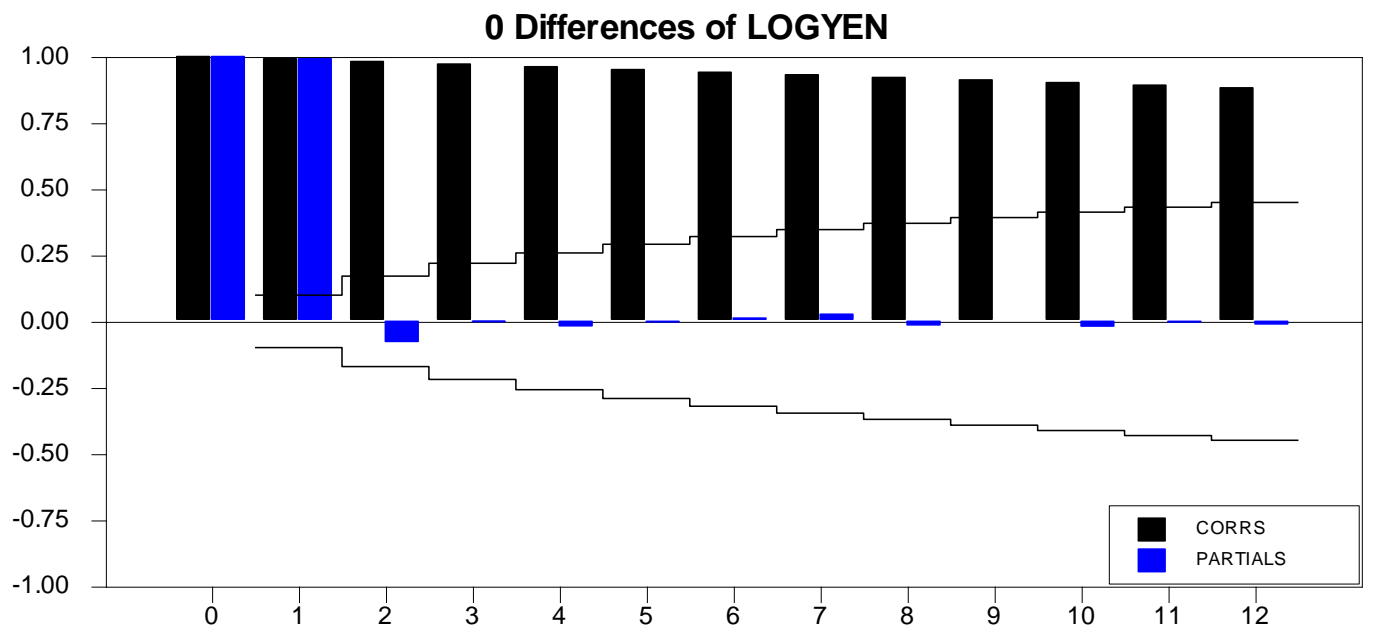

The above figures show that the changes in the logarithmic level of these two series indicate that the sample autocorrelation are very large and fail to decay. On the other hand, the partial autocorrelations are insignificantly different from zero, except for the first two displacements which are very large and equal to 1 for each of the series. 


\section{Stochastic Model And Data Description}

Graphical Presentation Of The Change In Logarithms Of The Canadian Dollar Exchange Rates Data

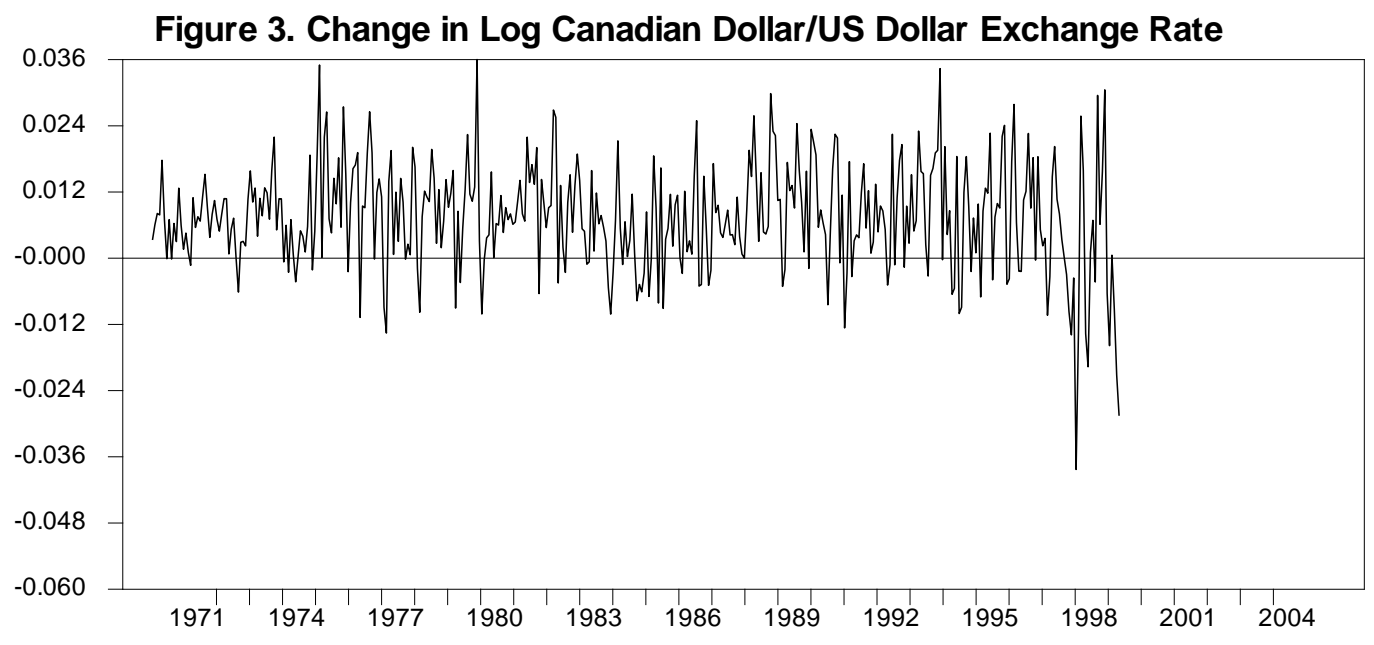

Graphical Presentation Of The Change In Logarithms Of The Japanese Yen

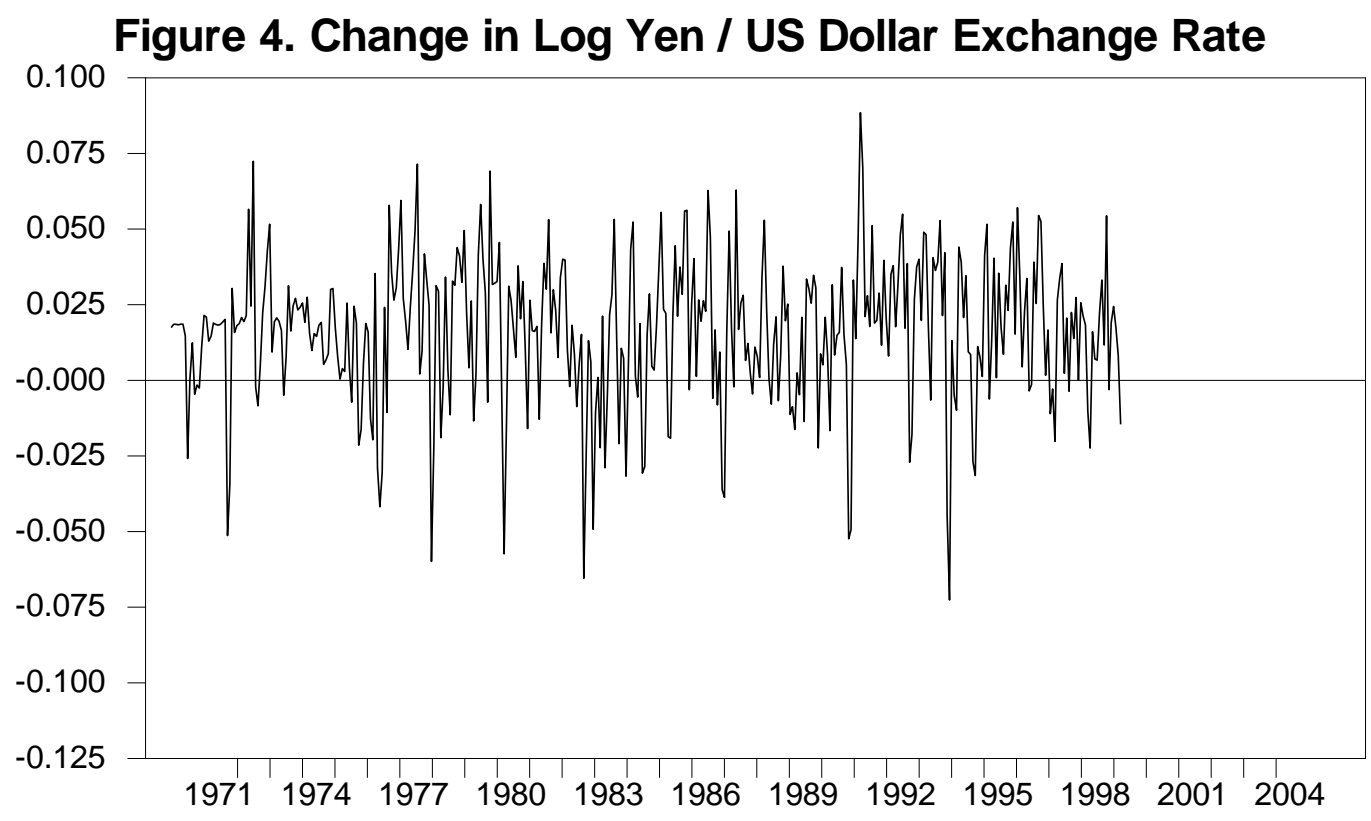

Both of these graphs show that the time series exhibit constant variance across time, criteria required by most statistical procedures. They also follow approximately a random walk process. Let's compute the correlograms for lags 0 and 1 for these two series. 
Sample And Partial Autocorrelation: Differences In The Logarithm Of The Canadian Dollar

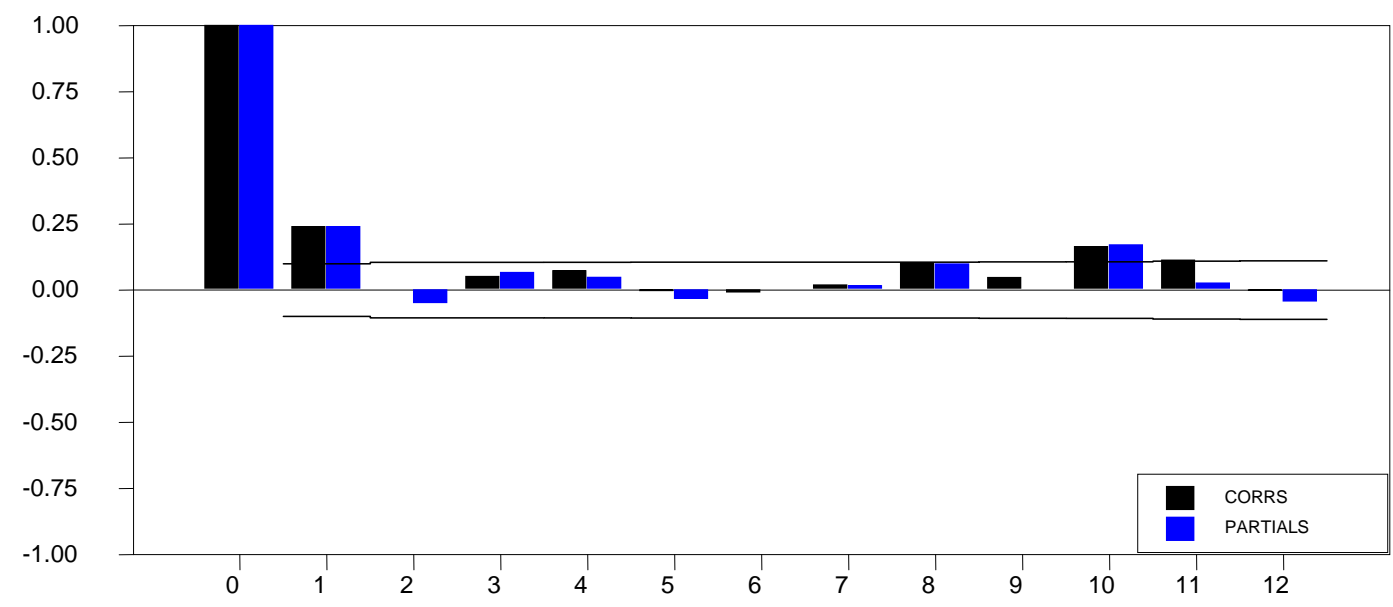

Sample And Partial Autocorrelation: Differences In The Logarithm Of The Japanese Yen

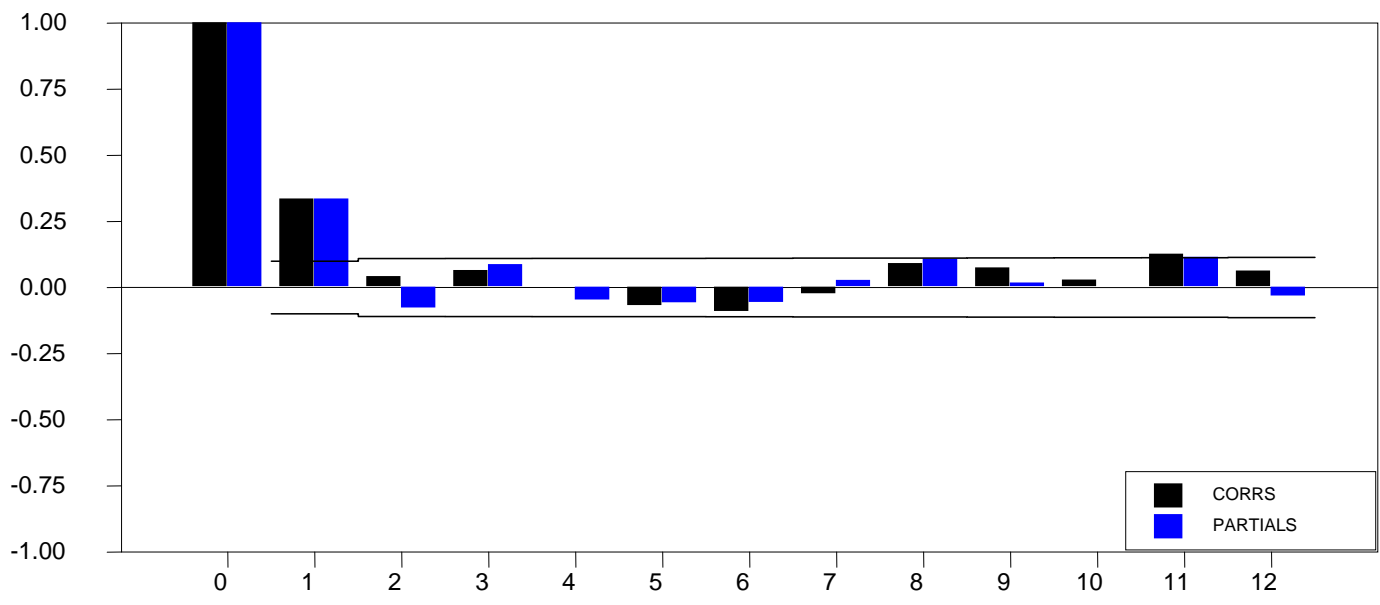

Except for the first two displacements, all the sample and partial autocorrelations are insignificantly different from zero, which indicates that we are in the presence of an integrated process of order 1 or I (1), implying that one has to find the best fitted deterministic and stochastic trends models in forecasting the behavior of the Japanese Yen and the Canadian Dollar against the US Dollar.

We used an ARMA $(3,3)$ dynamics in the disturbances, an Akaike Information Criterion (AIC) and a Schwarz Information Criterion (SIC) to determine the appropriate lags required for the best fitted model. The periods of forecast are from 1971:1 to 2002.12 and from 2003.1 to 2004.11 for out-of-sample forecast. Let's start with the deterministic model.

\section{FORECASTS OUTCOME AND DATA INTERPRETATION}

\section{AIC, SIC, And Best Deterministic Fitted Model}

We applied AIC and SIC to select the best fitted models. For the Canadian Dollar time series model we obtained the following SIC and AIC values: 
SIC And AIC For The Canadian Dollar Exchange Rate

\begin{tabular}{|c|c|c|c|c|}
\hline \multicolumn{5}{|c|}{$\underline{\text { SIC }}$} \\
\hline & 0 & 1 & 2 & 3 \\
\hline 0 & -5.4049360 & -6.5766250 & -7.4592395 & -7.8986284 \\
\hline 1 & -9.1828877 & -7.8552898 & -7.4250226 & -9.1638873 \\
\hline 2 & -9.1951866 & -9.1784645 & -9.1408262 & -9.2204121 \\
\hline 3 & -9.1751006 & -9.1579578 & -9.2110834 & -9.2060253 \\
\hline \multicolumn{5}{|c|}{$\underline{\text { AIC }}$} \\
\hline & 0 & 1 & 2 & 3 \\
\hline 0 & -5.4276569 & -6.6107064 & -7.5046813 & -7.9554307 \\
\hline 1 & -9.2170441 & -7.9008317 & -7.4819499 & -9.2322001 \\
\hline 2 & -9.2408290 & -9.2355175 & -9.2092898 & -9.3002863 \\
\hline 3 & -9.2322799 & -9.2265730 & -9.2911344 & -9.2975122 \\
\hline
\end{tabular}

The AIC and SBC suggest that we should select an ARMA $(2,3)$. For the Japanese Yen time series we obtained the following AIC AND SIC values:

SIC And AIC For The Japanese Yen Exchange Rate

$\underline{\text { SIC }}$

$\begin{array}{ccccc} & \mathbf{0} & \mathbf{1} & \mathbf{2} & \mathbf{3} \\ 0 & -3.6779890 & -4.9021529 & -5.7059113 & -6.1892287 \\ 1 & -7.1183014 & -7.2497435 & -7.2342139 & -7.2241465 \\ 2 & -7.2333412 & -7.2314952 & -7.2212619 & -7.2077664 \\ 3 & -7.2214987 & -7.2165451 & -7.2034071 & -7.1999613 \\ & & & & \\ 0 & \mathbf{A I C} & & \\ 1 & -3.6985653 & -4.9330173 & -5.7470638 & -6.2406694 \\ 2 & -7.1492259 & -7.2909762 & -7.2857548 & -7.2859956 \\ 3 & -7.2746545 & -7.2831368 & -7.2832319 & -7.2800646 \\ & -7.2732415 & -7.2786364 & -7.2758470 & -7.2827497\end{array}$

The AIC and SIC indicate that an ARMA $(1,1)$ should be selected to determine the best fitting forecasting deterministic model for the behavior of the Japanese Yen. The forecast period was from 1971:03 to 2002:12, and the out-of-sample forecasts period was from 2003:1 to 2004:11. We generated history and realization forecast for the period 1998:1 to 2004:11 and longer term forecasts up to 2010:12

The forecast was estimated by computing the upper and lower two standard error bands. The application of the Gauss-Newton method of estimation, which achieved convergence in 5 iterations, yielded the results which are found in Appendix 1. 
The table below reports the forecast error statistics between actual data and the forecasts:

Forecast Analysis For LOGYEN (Deterministic Model)

$\begin{array}{ll}\text { From } & 2003: 01 \text { to } 2004: 11 \\ \text { Mean Error } & -0.0186701 \\ \text { Mean Absolute Error } & 0.0236451 \\ \text { Root Mean Square Error } & 0.0311295 \\ \text { Mean Pct Error } & -0.0039823 \\ \text { Mean Abs Pct Error } & 0.0050320\end{array}$

The above results indicate that all the coefficients are statistically significant at $1 \%$ level and have the expected signs. The mean square error (MSE) is equal to 0.000969 and the root mean square error (RMSE) is equal to 0.0311295. To determine the relative performance of each model, we should compare these two means to those of the stochastic model below. Let's present first the graphical results of the deterministic forecasts model and present in the next section the results of the forecast of the stochastic model.

Graphical Presentations Of The Deterministic Forecasts For The Japanese Yen

Figure 6. Log Yen/US Dollar Exchange Rate: History, Forecast and Realization

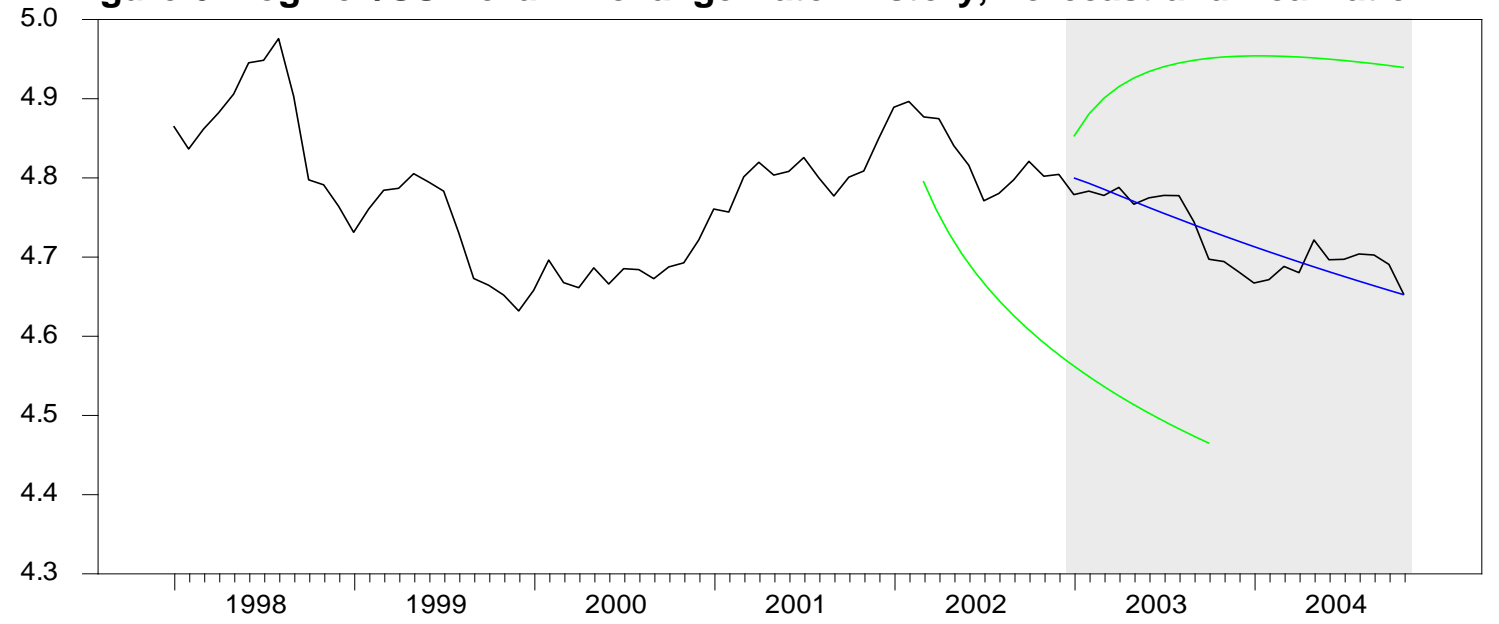


Graphical Representation, Unit Root Test, AIC, SBC And Best Stochastic Fitted Model

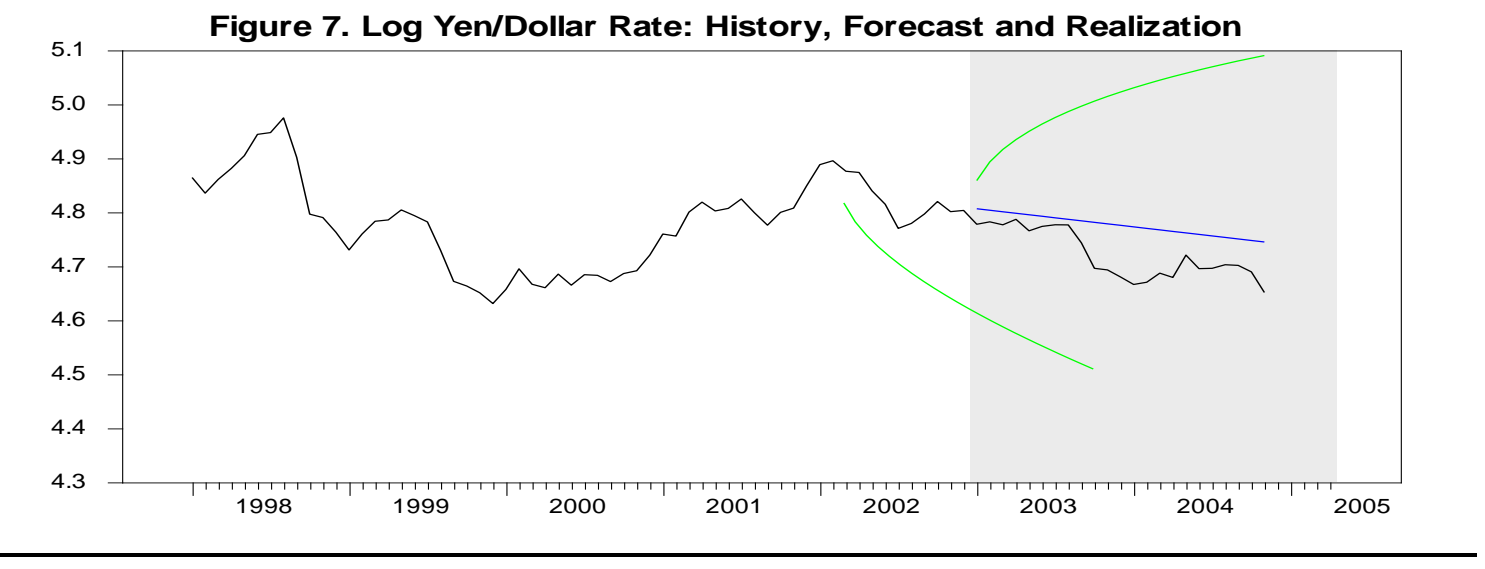

The sample and partial autocorrelation functions aforementioned advocate that we perform a unit root test. We used the Dickey-Fuller unit root test with intercept, trend, and three lags to check for the presence of a unit root.

\begin{tabular}{ll}
\multicolumn{2}{c}{ Dickey-Fuller Unit Root Test, Series LOGYEN } \\
Regression Run & from 1971:05 to 2003:12 \\
Observations & 393 \\
With intercept and trend with & 3 lags \\
T-test statistic & -2.48033 \\
Critical values: & $1 \%=-3.985$ \\
& $5 \%=-3.423$ \\
& $10 \%=-3.134$
\end{tabular}

As shown above, the test rejects the null hypothesis of an existence of a unit root. So let's proceed to select the best fitted stochastic forecast model using the AIC and SIC criteria. SIC selects an ARMA $(0,1)$ model and AIC selects an ARMA (2,3) model for the Japanese series. Based on the principle of parsimony (Diebold, 2004) we select an ARMA $(0,1)$ model. Because of the limited space, we have not reported the values of AIC and SIC. For comparative purposes the forecast period is similar to the one used for the Japanese Yen series. The forecast period is from 1971:03 to 2002:12, and for the out-of-sample forecasts from 2003:1 to 2004:11. We generated history and realization forecasts for the period 1998:1 to 2004:11 and longer term forecasts.

The forecast was estimated by computing the upper and lower two standard error bands. The application of the Gauss-Newton method of estimation, which achieved a convergence in 5 iterations, yielded the following results:

$\begin{array}{lc}\text { Forecast Analysis For LOGYEN (Stochastic Model) } \\ \text { From } & 2003: 01 \text { to } 2004: 11 \\ \text { Mean Error } & -0.0544265 \\ \text { Mean Absolute Error } & 0.0544265 \\ \text { Root Mean Square Error } & 0.0626557 \\ \text { Mean Pct Error } & -0.0115875 \\ \text { Mean Abs Pct Error } & 0.0115875 \\ \text { Root Mean Square Pct Error } & 0.0133728\end{array}$


For the stochastic forecasting model the mean square error (MSE) is equal to 0.003926 and the root mean square error (RMSE) is equal to 0.0626577, while for the deterministic forecasting model the figures were respectively 0.000969 and 0.0311295 .

Based on these figures one can conclude that the deterministic model has done slightly better job than the stochastic model even thought the absolute difference between the two does not seem that much significant. However, the graphical representation of these two forecasts brings out a sharp difference in the forecasting accuracy of these two models in both points and interval estimation. Even though these two models produced forecast within the two standard error bands, the deterministic forecasts proved to be more accurate in points and interval estimation in both the short and long horizon. Specifically, the realizations forecast-as shown in the figures 4 and 7 - are more accurately predicted by the deterministic model than by the stochastic model.

Let's apply the deterministic and stochastic models to the Canadian Dollar series. Because of the limited space we are not going to report all the results of the estimation. For comparative purpose, we applied the same analysis to both the Japanese Yen and the Canadian Dollar models.

The forecast period is similar to the one used in the previous model, meaning the forecast period from 1971:03 to 2002:12, and for the out-of-sample forecasts from 2003:1 to 2004:11. For comparative purposes we generated history and realization forecasts for the period 1998:1 to 2004:11 and longer term forecasts up to 2010:12.

\section{Dickey-Fuller Unit Root Test, Series LOGCAN}

$\begin{array}{ll}\text { Regression Run } & \text { From 1971:05 to 2002:12 } \\ \text { Observations } & 381 \\ \text { With intercept and trend } & \text { with } 3 \text { lags } \\ \text { T-test statistic } & -1.75049 \\ \text { Critical values: } & 1 \%=-3.986 \\ & 5 \%=-3.423 \\ & 10 \%=-3.134\end{array}$

Dickey-Fuller Unit Root Test rejects the null hypothesis of an existence of a unit root for both the deterministic model and stochastic model. So let's proceed to select the best fitted deterministic and stochastic forecast models using the AIC and SIC criteria. SIC and AIC selected an ARMA $(1,1)$ for the deterministic model and an ARMA $(0,1)$ for the stochastic models

Both methods were estimated by Gauss-Newton method. The upper and lower two standard error bands were constructed. The results of the estimation of the two models are provided in the Appendix 1.

$\begin{array}{ll}\text { Forecast Analysis For LOGCAN (Deterministic Model) } \\ \text { From } & 2003: 01 \text { to 2004:11 } \\ \text { Mean Error } & -0.1519979 \\ \text { Mean Absolute Error } & 0.1519979 \\ \text { Root Mean Square Error } & 0.1647121 \\ \text { Mean Pct Error } & -0.5602756 \\ \text { Mean Abs Pct Error } & 0.5602756 \\ \text { Root Mean Square Pct Error } & 0.6518864\end{array}$


The MSE is equal to 0.0271 and the RMSE is equal 0.1647121.

Forecast Analysis For LOGCAN (Stochastic Model)

$\begin{array}{ll}\text { From } & 2003: 01 \text { to } 2004: 11 \\ \text { Mean Error } & -0.1524524 \\ \text { Rean Absolute Error } & 0.1524524 \\ \text { Mean Pct Error } & 0.1651922 \\ \text { Mean Abs Pct Error } & -0.5619212 \\ \text { Root Mean Square Pct Error } & 0.5619212 \\ & 0.6537123\end{array}$

For the stochastic forecasting model the mean square error (MSE) is equal to 0.0272 and the root mean square error (RMSE) is equal to 0.1651922 compared to 0.0271 and 0.1647121 respectively for deterministic forecasting model.

Both MSE and RMSE suggest that there is no difference between the forecasts of the deterministic model and those of the stochastic model. However the graphical representation of these two forecasts is more revealing. The figures 5 and 7 below show that the two models produced more accurate points forecasts but inaccurate realization forecasts. The realization forecasts for both models lie outside the two standard error bands.

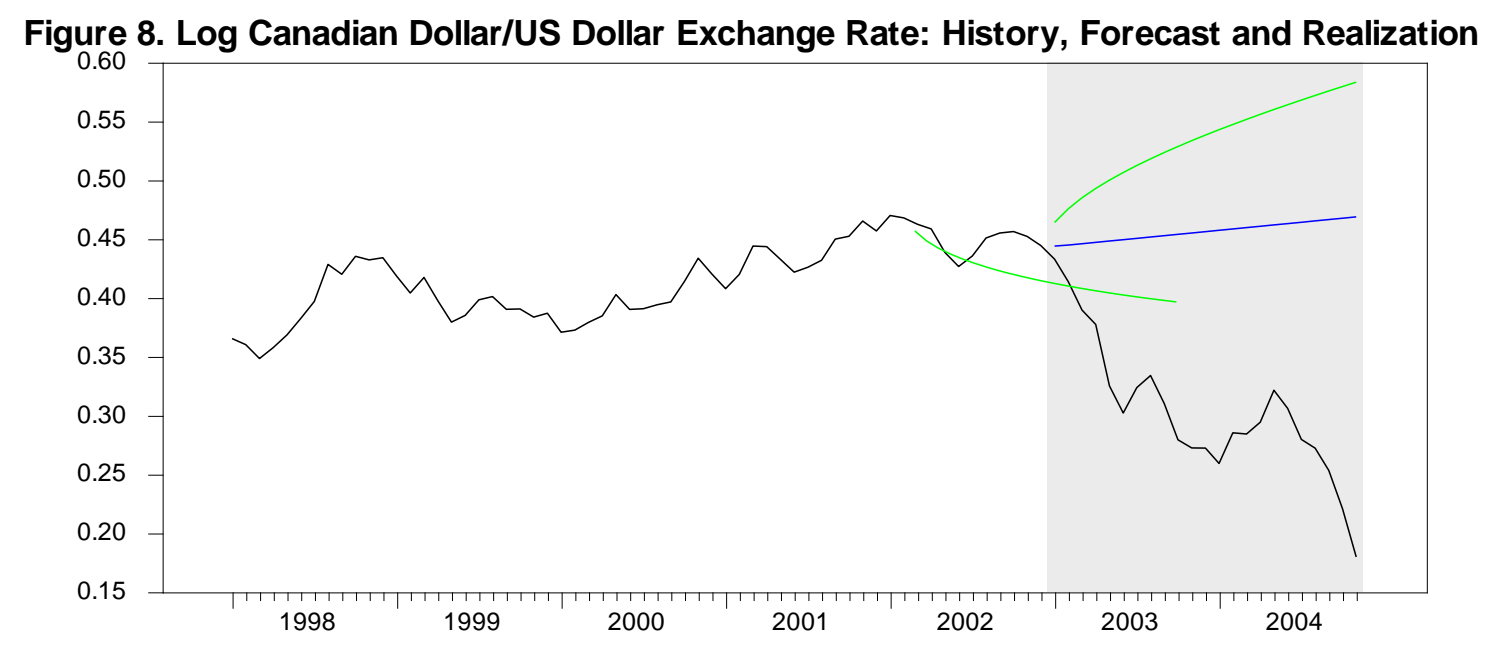


Figure 9. Log Canadian Dollar/US Dollar Exchange Rate: History and Long-Horizon Forecast

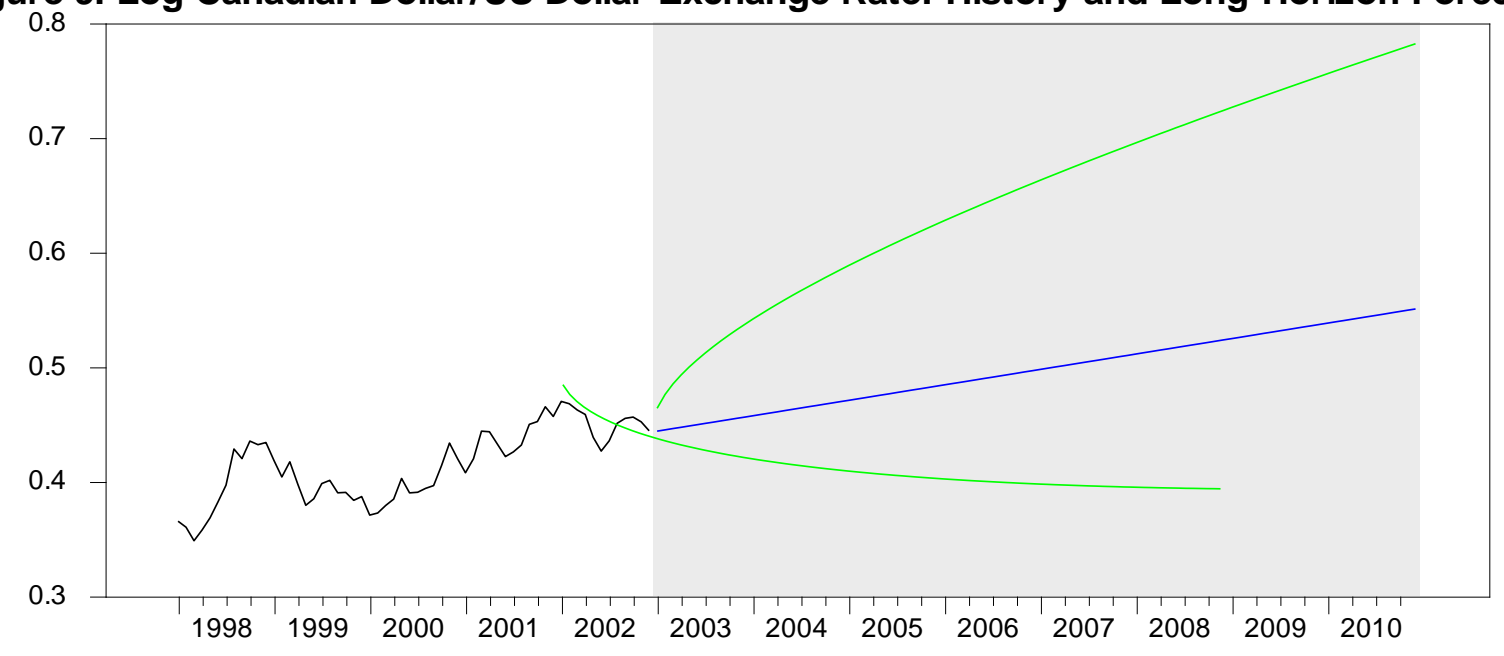

\section{CONCLUSION}

The deterministic and stochastic models we applied to forecast the Japanese Yen exchange rate against the US Dollar have produced robust results while the same models which we applied to the Canadian Dollar produced very poor forecasts. These results add to the evidence that forecasting exchange rates remains a mixture of art and science. The debate between the group that advocates more complex and sophisticated models with highly disaggregate intraday data and the group that believes that "right variables" are not included in the forecasting models is not ending soon.

\section{APPENDIX 1}

\section{$\underline{\text { Selected Deterministic Model }}$}

Box-Jenkins - Estimation by Gauss-Newton

Convergence in 8 Iterations. Final criterion was

Dependent Variable

Monthly Data

Usable Observations 383

Centered $\mathrm{R} * * 2 \quad 0.994890$

Uncentered R**2 0.998451

Mean of Dependent Variable

Std Error of Dependent Variable

\section{$0.0000006<0.0000100$ \\ LOGCAN}

From 1971:02 to 2002:12

Degrees of Freedom 379

R Bar **2 0.994850

$\mathrm{T} \times \mathrm{R} * * 2 \quad 382.407$

0.2105194714

0.1390455574

0.0099788290

0.0377396936

2.004418

55.133657

0.01238643

Sum of Squared Residuals

Durbin-Watson Statistic

Q(36-2)

Significance Level of Q

$\begin{array}{ll}\text { Variable } & \text { Coeff } \\ \text { CONSTANT } & -0.024290703 \\ \text { AR }\{1\} & 0.982308375 \\ \text { MA }\{1\} & 0.190272056 \\ \text { TIME }\{0\} & 0.001200402\end{array}$

Std Error

0.085106962

0.009741989

0.051081436

0.000313146
T-Stat

$-0.28541$

100.83242

3.72488

3.83336
Signif

0.77548303

0.00000000

0.00022512

0.00014796 


\section{$\underline{\text { Selected Stochastic Model }}$}

Box-Jenkins - Estimation by Gauss-Newton

Convergence in 5 Iterations. Final criterion was

Dependent Variable

$0.0000020<0.0000100$
LOGCAN

From 1971:02 to 2002:12

Usable Observations 383

Centered $\mathrm{R} * * 2 \quad 0.994844$

Uncentered R**2 0.998437

Mean of Dependent Variable

Std Error of Dependent Variable

Standard Error of Estimate

Sum of Squared Residuals

Durbin-Watson Statistic

$\mathrm{Q}(36-1)$

Significance Level of Q
Degrees of Freedom 381

R Bar **2 0.994830

$\mathrm{T} \times \mathrm{R} * * 2 \quad 382.401$

0.2105194714

0.1390455574

0.0099975271

0.0380811590

2.007374

54.393840

0.01935888

$\begin{array}{lllll}\text { Variable } & \text { Coeff } & \text { Std Error } & \text { T-Stat } & \text { Signif } \\ \text { CONSTANT } & 0.0011223640 & 0.0006040004 & 1.85822 & 0.06390924 \\ \text { MA }\{1\} & 0.1828710503 & 0.0504006680 & 3.62835 & 0.00032411\end{array}$

\section{$\underline{\text { Selected Deterministic Model }}$}

Box-Jenkins - Estimation by Gauss-Newton

Convergence in 5 Iterations. Final criterion was

Dependent Variable

Monthly Data

Usable Observations 383

Centered $\mathrm{R} * * 2 \quad 0.995746$

Uncentered $\mathrm{R} * * 2 \quad 0.999975$

Mean of Dependent Variable

Std Error of Dependent Variable

Standard Error of Estimate

Sum of Squared Residuals

Durbin-Watson Statistic

Q(36-2)

Significance Level of Q

\section{$0.0000015<0.0000100$ LOGYEN}

From 1971:02 To 2002:12

Degrees of Freedom 379

R Bar **2 0.995712

T x R**2 382.990

5.1594799845

0.3966365232

0.0259733938

0.2556799123

1.998075

41.915403

0.16512331

$\begin{array}{ll}\text { Variable } & \text { Coeff } \\ \text { CONSTANT } & 5.664496410 \\ \text { AR }\{1\} & 0.976852864 \\ \text { MA }\{1\} & 0.403164541 \\ \text { TIME }\{0\} & -0.002658506\end{array}$

Std Error
0.204709792
0.011980447
0.047618511
0.000798597

T-Stat

27.67086

81.53727

8.46655

$-3.32897$

\author{
Signif \\ 0.00000000 \\ 0.00000000 \\ 0.00000000 \\ 0.00095711
}




\section{Selected Stochastic Model}

Box-Jenkins - Estimation by Gauss-Newton

Convergence in 5 Iterations. Final criterion was $0.0000009<0.0000100$

Dependent Variable

LOGYEN

Monthly Data

Usable Observations 383

Centered $\mathrm{R} * * 2 \quad 0.995694$

Uncentered R**2 0.999975

Mean of Dependent Variable

From 1971:02 To 2002:12

Degrees of Freedom 381

R Bar **2 0.995683

$\mathrm{T} \times \mathrm{R} * * 2 \quad 382.990$

5.1594799845

Std Error of Dependent Variable $\quad 0.3966365232$

Standard Error of Estimate $\quad 0.0260614619$

Sum of Squared Residuals $\quad 0.2587751221$

Durbin-Watson Statistic $\quad 2.006721$

$\mathrm{Q}(36-1)$

Significance Level of Q

42.127496

0.18980377

$\begin{array}{lllll}\text { Variable } & \text { Coeff } & \text { Std Error } & \text { T-Stat } & \text { Signif } \\ \text { CONSTANT } & -0.002796489 & 0.001857621 & -1.50541 & 0.13304618 \\ \text { MA }\{1\} & 0.396317754 & 0.047111387 & 8.41236 & 0.00000000\end{array}$

\section{ENDNOTES}

1. Neely, Christopher J. and Lucio Sarno, How Well Do Monetary Fundamentals Forecast Exchange Rates?, Federal Reserve Bank of Saint Louis Review, Sep/Oct 2002, Vol. 84 Issue 5, p. 21.

2. Dornbush, R., Expectations and exchange rate dynamics, JPE 84(6), 1976, 1161-1176.

3. Neely, Christopher J. and Lucio Sarno. How Well Do Monetary Fundamentals Forecast Exchange Rates?, Federal Reserve Bank of Saint Louis Review, Sep/Oct 2002, Vol. 84, Issue 5, p. 21.

4. Chen, An-Sing and Mark T. leung, A Bayesian vector error correction model for forecasting exchange rates, Computers \& Operations Research. New York, Vol. 30, Iss. 6, May 2003, pg. 887.

5. Sarno, Lucio and Giorgio Valente, Journal of International Money and Finance, Kidlington: Vol. 24, Iss. 2, March 2005, pp. 363.

6. Yu, Lean, Shouyang Wang, and K. K. lai, A novel nonlinear ensemble forecasting model incorporating GLAR and ANN for foreign exchange rates, Computers \& Operations Research. New York: Oct 2005, Vol. 32, Iss. 10, pg. 2523.

7. Neely, Christopher J. and Lucio Sarno, How Well Do Monetary Fundamentals Forecast Exchange Rates?, Federal Reserve Bank of Saint Louis Review, Sep/Oct 2002, Vol. 84 Issue 5, p.21.

8. Huang, Wei, Lai, K. K., Nakamori, Y., and Wang, Shouyang. Forecasting Foreign Exchange Rates With Artificial Neural Networks: A Review, International Journal of Information Technology \& Decision Making, Mar 2004, Vol. 3 Issue 1, p 145, 21p.

9. Neely, Christopher J. and Lucio Sarno, How Well Do Monetary Fundamentals Forecast Exchange Rates?, Federal Reserve Bank of Saint Louis Review, Sep/Oct 2002, Vol. 84 Issue 5, p. 21.

10. Chen, An-Sing and Mark T. leung, A Bayesian vector error correction model for forecasting exchange rates, Computers \& Operations Research, New York. Vol. 30, Iss. 6, May 2003, pg. 887.

11. Yu, Lean, Shouyang Wang, and K. K. lai, A novel nonlinear ensemble forecasting model incorporating GLAR and ANN for foreign exchange rates, Computers \& Operations Research, New York: Oct 2005, Vol.32, Iss. 10, pg. 2523. 


\section{ENDNOTES}

${ }^{1}$ Neely, Christopher J., and Lucio Sarno. "How Well Do Monetary Fundamentals Forecast Exchange Rates?" Federal Reserve Bank of Saint Louis Review ; Sep/Oct2002, Vol. 84 Issue 5, p.21

${ }^{2}$ Dornbush, R. (1976) "Expectations and exchange rate dynamics", JPE 84(6), 1161-1176

${ }^{3}$ Neely, Christopher J., and Lucio Sarno. "How Well Do Monetary Fundamentals Forecast Exchange Rates?" Federal Reserve Bank of Saint Louis Review ; Sep/Oct2002, Vol. 84 Issue 5, p.21

${ }^{4}$ Chen, An-Sing and Mark T leung " A Bayesian vector error correction model for forecasting exchange rates" Computers \& Operations Research. New York.Vol.30, Iss. 6, $\quad$ May 2003, pg. 887

${ }^{5}$ Sarno, Lucio and Giorgio Valente. Journal of International Money and Finance. Kidlington: Vol.24, Iss. 2; March 2005, pp. 363.

${ }^{6} \mathrm{Yu}$, Lean, Shouyang Wang, and KK lai.". A novel nonlinear ensemble forecasting model incorporating GLAR and ANN for foreign exchange rates Computers \& Operations Research. New York: Oct 2005, Vol.32, Iss. 10; pg. 2523

${ }^{7}$ Neely, Christopher J., and Lucio Sarno. "How Well Do Monetary Fundamentals Forecast Exchange Rates?" Federal Reserve Bank of Saint Louis Review ; Sep/Oct2002, Vol. 84 Issue 5, p.21

${ }^{8}$ HUANG, WEI; LAI, K. K.; NAKAMORI, Y.; WANG, SHOUYANG. "FORECASTING FOREIGN EXCHANGE RATES WITH ARTIFICIAL NEURAL NETWORKS: A REVIEW." International Journal of Information Technology \& Decision Making, Mar2004, Vol. 3 Issue 1, p145, 21p 
${ }^{9}$ Anderson, Torben G, Tim Bollerslev, Francis X. Diebold, and Paul Labys. "Modeling and forecasting realized volatility” Econometrica. Evanston: Vol.71, Iss. 2; March 2003, pp. 579.

${ }^{10}$ Diebold, Francis X, Elements of forecasting, Thomson:South :Western, United States, Third Edition, 2004

${ }^{11}$ Diebold, Francis X, Elements of forecasting, Thomson:South: Western, United States, Third Edition 2004 